\title{
A new concept for growth restriction during solidification
}

\author{
Z. Fan*, F. Gao, L. Zhou, and S. Z. Lu
}

BCAST, Brunel University London, Uxbridge, Middlesex, UB8 3PH, UK.

*Corresponding author. Tel.: +44 1895 266406; Fax: +44 1895 269758; E-mail address: Zhongyun.Fan@brunel.ac.uk

\begin{abstract}
:
Growth restriction refers to the phenomenon of reduced growth velocity due to the solute enrichment/depletion at the solid/liquid interface during alloy solidification. Although significant progress has been made to understand this phenomenon, so far there has been no effective parameter to quantify growth restriction. In this paper, we have derived a new parameter, $\beta$, to quantify the growth restriction in multicomponent systems effectively, and which incorporates the nature of solutes, solute concentrations and solidification conditions holistically. Theoretical analysis and phase field simulations have confirmed that growth velocity is a unique function of $\beta$ regardless of the nature of solutes, solute concentrations and solidification conditions, but it is not a unique function of the widely used growth restriction factor, $Q$. Our analysis suggests that the overall $\beta$ for a multicomponent alloy system can be either calculated accurately by the ratio of the liquid fraction to the solid fraction $\left(\beta=f_{L} / f_{S}\right)$ or approximated with great confidence by a linear addition of the $\beta$ values of the constituent binary systems. In addition, we have shown theoretically that for a given alloy system solidifying under a given undercooling, there is a critical solute concentration, below which solidification becomes partitionless and therefore there is no growth restriction during solidification. Furthermore, our analysis has shown that the physical origin of growth restriction is the blockage of the supply of the critical elements for crystal growth, i.e., solvent atoms in the case of eutectic-forming.
\end{abstract}

Keywords: Solidification, Growth restriction, Modelling, Undercooling 


\section{Introduction}

During solidification of metallic alloys, solutes partition differentially between the solid and liquid phases, resulting in either accumulation or depletion of solutes at the solid/liquid interface depending on the nature of the solute(s) in a given alloy. It has been long recognised that such accumulation/depletion of solutes leads to a slower growth rate of the solid phase [1], and this phenomenon is usually referred to as growth restriction in the literature. Historically, Cibula [1] was the first person to recognise such a phenomenon by suggesting that there is a concentration gradient in the liquid around a growing solid during solidification. Ivantsov [2] discussed the solute field in the liquid around a growing solid and proposed the concept of constitutional supercooling, which was described more rigorously later by Rutter and Chalmers [3], and formulated quantitatively by Tiller et al. [4]. Soon after, Winegard and Chalmers [5] made the connection between constitutional supercooling and equiaxed grain formation during solidification. Since then the effect of solute concentration on grain refinement has been demonstrated experimentally by a number of researchers [e.g., 6-10].

Our current knowledge of growth restriction and its effect on solidification is mainly obtained from the research on grain refinement. Due to the desire for homogenous microstructure, improved crack susceptibility and better machinability, grain refinement has been widely investigated both experimentally and theoretically over the past decades, especially in Aland Mg-alloys (see reviews in Refs. [11-13]). In the beginning, attention was focused mainly on the importance of the nucleant particles on grain refinement $[1,14,15]$. However, Wallace [16] recognized the role of solute on grain refinement, and Tarshis et al. [17] demonstrated that in a range of Ni- and Al-based alloys the addition of solute led to significant grain refinement. Since then, substantial attentions have also been paid to the solute effect on grain refinement [13, 18, 19]. Easton and StJohn [13] reviewed the mechanisms of grain refinement and divided the theoretical and experimental work into two categories, the "nucleant paradigm" and the "solute paradigm". The former emphasises the importance of the nucleant particles on grain refinement, while the latter incorporates the influence of solutes on the grain refinement process. It is now well accepted that effective grain refinement requires the presence of both potent nucleant particles with adequate number density and sufficient solute contents [20]. For instance, it has been demonstrated that solidification of alloys without the presence of adequate solute leads to a columnar microstructure even if an exceptionally large 
number of potent nucleant particles are present in the melt [21, 22]. It is generally accepted that increasing solute content results in a later start and slower rate of recalescence, which in turn allows more time for further grain initiations to proceed.

So far, there has been substantial effort dedicated to a quantitative description of growth restriction during solidification (see review in Ref. [23]). Tarshis et al. [17] proposed a parameter, the constitutional supercooling parameter $P$, to quantify the solute effect, and correlated grain size with $P$ in $\mathrm{Ni}$ - and Al-based alloys:

$$
P=\frac{m C_{0}(k-1)}{k}
$$

where $m$ is the liquidus slope in a linear phase diagram, $k$ is the equilibrium solute partition coefficient, and $C_{0}$ is the solute content in the alloy melt. Spittle and Sadli [24] studied the effect of $\mathrm{Cr}, \mathrm{Cu}, \mathrm{Fe}, \mathrm{Mg}, \mathrm{Mn}, \mathrm{Si}, \mathrm{Zn}$ and $\mathrm{Zr}$ on the grain size of high purity $\mathrm{Al}$ with and without $0.2 \mathrm{wt} . \%$ addition of Al-5Ti-1B grain refiner. Their results showed that there appears to be a good correlation between the grain size and the constitutional supercooling parameter $P$.

Another more popular parameter for quantifying growth restriction is the growth restriction factor, $Q$, which was first defined by Maxwell and Hellawell [25] as $1 / X$ in their modelling of spherical growth restricted by the partitioning of a single solute. This factor $(1 / X)$ was considered to be the growth restriction factor, and denoted as $Q$ later by other researchers:

$$
Q=m C_{0}(k-1)
$$

From Eqs. (1) and (2), one has $P=Q / k$. Greer et al. [26] replotted the grain size data of Spittle and Sadli [24] as a function of the growth restriction factor $Q$, and found that $Q$ is a better parameter than $P$ for quantifying the degree of growth restriction. In addition, it has been suggested that $Q$ could be defined as the available undercooling for the formation of the initial solid and therefore $Q$ can be expressed as [27]:

$$
Q=\left(\frac{\partial\left(\Delta T_{C}\right)}{\partial f_{S}}\right)_{f_{S \rightarrow 0}}
$$

where $\Delta T_{C}$ is the constitutional undercooling, and $f_{S}$ is the solid fraction. One of the advantages of Eq. (3) is that it offers a thermodynamic approach to predicting the $Q$ value for multicomponent alloys $[28,29]$. However, the approach to the growth restriction factor of a 
multicomponent system commonly used in the literature is often a simple linear addition of those for the constituent binary systems $[8,10,30]$ :

$$
Q=\sum_{i=1}^{n} m_{i} C_{0 i}\left(k_{i}-1\right)
$$

where $i$ refers to the individual solute in the multicomponent system.

Hodaj and Durand [31] proposed another parameter, $U$, to quantify the growth restriction of solutes in multicomponent systems by considering the difference in diffusion coefficients of solutes during solidification under low undercooling,

$$
U=D \sum_{i} \frac{1}{D_{i}} m_{i} C_{i}\left(k_{i}-1\right)
$$

where $D$ is the self-diffusion coefficient of the solvent, and $D_{i}$ is the diffusion coefficient of the $i^{\text {th }}$ solute in the liquid. In Eq. (5) the contributions of the constituent solutes are weighted inversely by their diffusivities $D_{i}$. However, it is usually difficult to obtain reliable data for solute diffusivities in liquid alloys, and therefore, it is a common practice to use a constant diffusion coefficient for all the solutes during numerical modelling of solidification processes.

The parameters, $P$ and $Q$, have been used extensively to account for the experimentally observed effect of solutes on grain size [10, 17, 24, 30, 32-35]. Tarshis et al. [17] and Spittle and Sadli [24] explained their experimental results in terms of $P$ and found that their measured grain sizes were closely related to the parameter $P$. However, more work $[10,30$, 32-35] has focused on the relationship between grain size and the growth restriction factor $Q$. In addition, a few theoretical models for predicting grain size have also been developed involving $Q$ [25-27, 36-38]. For example, Maxwell and Hellawell [25] developed a simple model for spherical growth during solidification of an isothermal melt, in which the parameter $1 / X(1 / X=Q)$ was identified as the growth restriction parameter. Based on the Maxwell and Hellawell model [25], Greer et al. [26] developed a numerical model for predicting grain size of Al-alloys with grain refiner addition, and found that a grain grows from a refiner particle at an undercooling inversely proportional to the particle diameter, which has been referred to as the free growth model:

$$
\Delta T_{f g}=\frac{4 \gamma}{\Delta S_{v} d}
$$


where $\Delta T_{f g}$ is free growth undercooling, $\gamma$ is the solid/liquid interfacial energy, $\Delta S_{v}$ is entropy of fusion per unit volume, $d$ is particle diameter. They found that their numerical predictions [26] agree well with the experimental data of Spittle and Sadli [24] up to $400 \mu \mathrm{m}$, but not beyond that. In addition, extensive experimental work has revealed an empirical relationship between the average grain size $(\bar{l})$ and the growth restriction factor $Q$ [32, 37, 39-42]:

$$
\bar{l}=a+\frac{b}{Q}
$$

where $a$ and $b$ are constants. It was believed that $a$ is related to the number density of active nucleant particles and $b$ is related to the potency of the nucleant particles [42, 43]. Further analysis has led to the development of the interdependence theory [37]. Furthermore, in the recent years we have seen more theoretical models for grain size prediction $[36,44,45]$, which involve the growth restriction factor $Q$ either directly or indirectly.

However, although experimental results in dilute binary alloys have demonstrated that grain size decreases monotonically with increasing $Q$, there has been increasing evidence to show that $Q$ does not always work well for quantifying growth restriction during solidification. When examining the effect of solute content on grain size over the entire range of hypoeutectic compositions in binary alloys, $\mathrm{Xu}$ et al. [46] found that the relationship between the grain size and $P$ or $Q$ is not monotonic at high alloy concentrations [46]. They suggested that the grain size decreases monotonically with increasing freezing range of aluminium alloys, with the minimum grain size occurring at the maximum freezing range. However, Liu et al. [47] found that their experimentally measured grain size of $\mathrm{Zn}$ alloys as a function of solute content cannot be fully explained using $Q, P$, or freezing range individually, suggesting that none of these three parameters alone can be fully correlated to grain refinement.

In addition, the reliability of some of the grain size data in the literature, particularly those for dilute alloys, is questionable. The majority of the previous grain size data were obtained by the standard Alcan TP-1 test [48], in which grain size is measured from the central region of a cross-section $38 \mathrm{~mm}$ above the base of the TP-1 sample. More recent experimental results have confirmed that the microstructures of most dilute alloys are columnar in the vertical section although the corresponding cross-section of the same sample shows an apparently equiaxed structure [21, 49]. Most recently, Zhou [50] repeated the experiments of Spittle and Sadli [24], but examined the resultant microstructure in both the cross-section and the vertical 
section of the TP-1 samples of all the alloys. It was demonstrated clearly that after the columnar to equiaxed transition (CET) the grain size decreases only moderately with increasing solute content, suggesting that the solute effect on grain size is not as significant as we have thought previously.

The present work aims to develop a new parameter to quantify the growth restriction effect of solute by considering the nature of the solutes, solute concentrations and solidification conditions holistically. The newly developed growth restriction parameter is validated by phase field simulations.

\section{A new concept for growth restriction}

For diffusion controlled spherical growth, the resultant exact expression for the growth velocity $V$ of a grain of radius $r$ is given by the following equation [51,52]:

$$
V=\frac{\lambda^{2} D_{i}}{2 r}
$$

where $\lambda$ is a parameter related to the instantaneous undercooling. Therefore, $\lambda^{2} / 2$ is taken as the growth coefficient, and its inverse, $2 / \lambda^{2}$, can be defined as the growth restriction coefficient.

In the early analysis of the growth of spherical precipitates from a supersaturated solid solution, Zener [52] used the solute supersaturation, $\alpha$, to approximate the growth restriction coefficient:

$$
\frac{\lambda^{2}}{2}=\alpha
$$

and for spherical growth during solidification, $\alpha$ is defined by the following equation:

$$
\alpha=\frac{C_{L}-C_{0}}{C_{L}-C_{S}}
$$

where $C_{L}$ and $C_{S}$ are the solute contents in the liquid and the solid phases at the solid/liquid interface, respectively, as illustrated in Fig. 1. However, the Zener approximation (Eq. (9)) is only applicable to the cases where $\alpha \rightarrow 0$ [52].

In their approach to the same problem by Aaron et al. [51], $\lambda$ was approximated by the following equation: 


$$
\lambda=\left(\frac{-S}{2 \pi^{1 / 2}}\right)+\left(\frac{S^{2}}{4 \pi}-S\right)^{1 / 2}
$$

and for spherical growth during isothermal solidification, Maxwell and Hellawell [25] derived the follow expression for $S$ :

$$
S=\frac{2\left(C_{L}-C_{0}\right)}{C_{S}-C_{L}}
$$

However, similar to Eq. (9), Eqs. (11) and (12) are only applicable to cases where $\alpha \rightarrow 0$ [25, 52].

Recently, Fan and Lu [53] developed a general analytical solution for spherical growth during isothermal solidification, and obtained the following exact solution:

$$
\frac{\lambda^{2}}{2}\left[1-\frac{1}{2} \sqrt{\pi} \lambda \exp \left(\frac{\lambda^{2}}{4}\right) \operatorname{erfc}\left(\frac{\lambda}{2}\right)\right]=\alpha
$$

Unfortunately, Eq. (13) is implicit. An explicit expression of $\lambda^{2} / 2$ as a function of $\alpha$ was then obtained numerically from Eq. (13) and given by the following equation:

$$
\frac{\lambda^{2}}{2}=\frac{\alpha}{1-\alpha}(1+\sqrt{\alpha}+\alpha)
$$

Eq. (14) is applicable to all the cases where $0<\alpha<1$. Then one has [53]:

$$
V=\frac{\alpha}{1-\alpha}(1+\sqrt{\alpha}+\alpha) \frac{D_{i}}{r}
$$

and the growth restriction coefficient becomes

$$
\frac{2}{\lambda^{2}}=\frac{1-\alpha}{\alpha(1+\sqrt{\alpha}+\alpha)}
$$

From the definitions of $\alpha$ and $Q$, one gets:

$$
\alpha=\frac{1}{\frac{m C_{0}(k-1)}{\Delta T}-(k-1)}=\frac{1}{\frac{Q}{\Delta T}-(k-1)} .
$$

From Eqs. (16) and (17), one can calculate the growth restriction coefficient, $2 / \lambda^{2}$, as a function of $Q / \Delta T$ ( Fig. 2). It is obvious in Fig. 2 that the intercept of $2 / \lambda^{2}$ at $Q / \Delta T$ axis becomes $k$. For a given $k$ value (i.e., for a given solute), when $Q / \Delta T \leq k$, the growth restriction coefficient $2 / \lambda^{2}=0$; while when $Q / \Delta T>k, 2 / \lambda^{2}$ increases monotonically with 
increasing $Q / \Delta T$. However, $2 / \lambda^{2}$ is not a unique function of $Q / \Delta T$; and as the value of $k$ increases the curve shifts towards the right hand side of the plot (Fig. 2). This suggests that the growth restriction coefficient $2 / \lambda^{2}$ is a function of $Q, \Delta T$ and $k$; and any of these parameters alone will not be adequate to describe growth restriction. In addition, Fig. 2 also provides a clear theoretical reasoning for why $Q$ is not additive for multicomponent systems.

In this work, we define a new parameter, the growth restriction parameter, $\beta$ :

$$
\beta=\frac{m C_{0}(k-1)}{\Delta T}-k=\frac{Q}{\Delta T}-k
$$

Fig. 3 shows the growth restriction coefficient, $2 / \lambda^{2}$, as a function of growth restriction parameter, $\beta$. In Fig. 3, $2 / \lambda^{2}$ becomes a unique function of $\beta$, being independent of the nature of solutes; and $2 / \lambda^{2}$ increases monotonically with increasing $\beta$ for all solutes. Therefore, $\beta$ can be used as a measure of the growth restriction coefficient although $\beta$ does not equal to the growth restriction coefficient. By assuming that there are no interactions between solutes, one would intuitively expect that $\beta$ of a multicomponent system can be expressed by the linear additivity of the constituent binary system $\left(\beta_{i}\right)$ :

$$
\beta=\sum_{i=1}^{n} \beta_{i}
$$

Substituting $\Delta T=m\left(C_{0}-C_{L}\right)$ and $k=\frac{C_{S}}{C_{L}}$ into Eq. (18), one obtains

$$
\beta=\frac{C_{0}-C_{S}}{C_{L}-C_{0}}=\frac{f_{L}}{f_{S}}
$$

where $f_{L}$ and $f_{S}$ are the phase fractions of the liquid and the solid, respectively. Eq. (20) suggests that $\beta$ is the ratio of the liquid phase fraction, $f_{L}$, to the solid phase fraction, $f_{S}$. I addition, Eq. (20) also provides heuristically a thermodynamic approach to calculating the $\beta$ values of multicomponent systems using CALPHAD software and associated thermodynamic databases. Fig. 4 compares the calculated $\beta$ values from Eqs. (19) and (20) for a number of Al-based binary alloy systems (Al-Si, Al-Ti, Al-Fe and Al-Cu), ternary alloy systems (Al-SiFe and Al-Si-Ti), and quaternary alloy systems (Al-Si-Fe-Cu and Al-Si-Fe-Ti). Fig. 4 shows that the $\beta$ values for the various alloy systems calculated from the additivity equation (Eq. (19)) are in very good agreement with those calculated from Eq. (20). This suggests that the additivity approach (Eq. (19)) is applicable to multicomponent systems, in direct contrast to the case of $Q$, which is obviously not additive (see Fig. 2). 


\section{Validation of $\beta$ by phase field simulation}

Phase field modelling has been widely used for the simulation of microstructural evolution during solidification processes [54-56]. In this study, we used the phase field approach to investigate the effect of solutes on growth restriction in Al-alloys under isothermal solidification conditions. The MICRESS software [57] was used for all the phase field simulations with the set-up described in Ref. [58]. Since the thermal diffusion distance is generally $10^{3}$ times larger than the average grain size, a melt with a sufficiently small volume can be approximated as spatially isothermal, which is a widely adopted approach in solidification research [25, 26, 28]. Planar growth was imposed to avoid the effect of curvature undercooling. The binary systems (Al-Si, Al-Fe, Al-Cu, and Al-Ti) and the ternary systems (Al-Si-Fe and Al-Si-Ti) were used in the present work, with different levels of undercooling, i.e. 0.5 and $1 \mathrm{~K}$. The detailed alloy composition, solidification condition and the corresponding $Q, \beta$ and growth velocity obtained by phase field simulations are summarised in the appendix.

The values of $m$ and $k$ in the binary Al-alloy systems were obtained by linear fitting of the liquidus and solidus in the phase diagrams at the Al-rich end calculated from the PanAl database using the Pandat software. The parameters used for the phase field simulations are listed in Table 1. For simplicity, we have assumed that the presence of solutes at reasonably low concentrations has no effect on interfacial energy, entropy of fusion or diffusion coefficients. Meanwhile, the diffusion coefficients of the solutes in the liquid Al were assumed to have the same value. The grid size and interface mobility were calibrated during the simulation; and it is confirmed that the variation of grid size from 0.1 to $1 \mu \mathrm{m}$ and the interface mobility from 0.1 to $1 \mathrm{~cm}^{4} / \mathrm{Js}_{\mathrm{s}}$ have no significant effect on the growth velocity of the planar interface. The steady state velocity of the planar interface is obtained by linearly fitting the relationship between distance and time.

The resultant growth velocity for the various alloys, at two different levels of undercooling, 0.5 and $1.0 \mathrm{~K}$, is plotted against $Q$ in Fig. 5. It is not surprising to see that there is considerable scatter in the growth velocity data against $Q$, which can be attributed to the variation in partition coefficient $(k)$ and/or undercooling $(\Delta T)$ for a given value of $Q$. For example, the $Q$ value is 0.29 for Al-0.05Si alloy (labelled by the solid arrows in Fig. 5), but the growth velocity at $\Delta T=1.0 \mathrm{~K}$ is $283 \mu \mathrm{m} / \mathrm{s}$ which is more than twice of that at $\Delta T=0.5 \mathrm{~K}(122 \mu \mathrm{m} / \mathrm{s})$. A similar situation is also found in the case of Al-0.1Si alloy (labelled by the dashed arrows 
in Fig. 5). In addition, Fig. 5 suggests that systems containing peritectic-forming elements (e.g. Al-Ti) have higher growth velocity for a given $Q$ value compared with those containing eutectic-forming elements (e.g. Al-Fe and Al-Si). Therefore, it can be concluded that the growth velocity is not a unique function of $Q$.

However, when the same growth velocities are plotted against their corresponding $\beta$ values in Fig. 6, all the growth velocity data for the different alloy systems with varying $k$ and $\Delta T$ are consistently aligned to one curve (the dashed curve). Fig. 6 suggests that the growth velocity is a unique function of $\beta$, regardless of the nature of solutes $(k)$, solute concentration $\left(C_{0}\right)$ and solidification condition $(\Delta T)$. Therefore, $\beta$ is a more effective parameter than $Q$ for quantifying the growth restriction during solidification, since it captures not only the thermodynamic characteristics of the solutes but also the effect of solidification condition.

\section{General discussion}

\subsection{Effect of solute interactions on $\beta$ in multicomponent systems}

In the present work, only dilute alloys are considered, and therefore the interactions between solutes are expected to be small and ignored when the linear additivity of $\beta$ (Eq. (19)) is applied to multicomponent systems. In this section, we analyse the effect of solute interactions on $\beta$ to validate this assumption.

In a dilute multicomponent alloy (denoted as A-B-C in general), the interaction between solutes $\mathrm{B}$ and $\mathrm{C}$ can be expressed by the regular solution approximation when the ternary interaction can be ignored. Thus, the excess Gibbs free energy of the liquid due to the interaction between solutes $\mathrm{B}$ and $\mathrm{C}, \Delta G_{B, C}^{e x}$, can be expressed as:

$$
\Delta G_{B, C}^{e x}=L_{B C} x_{B} x_{C}
$$

where $L_{B C}$ is the interaction parameter between solutes $\mathrm{B}$ and $\mathrm{C}, x_{\mathrm{B}}$ and $x_{\mathrm{C}}$ are the molar fractions of the solutes $B$ and $C$, respectively. For the ternary A-B-C system, the interactions between the solvent and the solutes (A-B and A-C) play a dominant role in determining the phase diagram, while the interaction between the solutes (B-C) affects the phase diagram only when $L_{B C}$ is large in absolute value, either negative or positive. A negative $L_{B C}$ value means attractive interaction; a positive $L_{B C}$ value suggests a repulsive interaction; and $L_{B C}=0$ refers to an ideal solution. 
In order to investigate the effect of solute interactions in the liquid phase, a strong solute interaction $\left(L_{B C}= \pm 125 \mathrm{~kJ} / \mathrm{mol}\right)$ was deliberately assigned to the Al-Fe-Si system to stretch its possible effect since the actual absolute $L_{B C}$ values for dilute multicomponent Al-alloys are usually much less than $125 \mathrm{~kJ} / \mathrm{mole}$ (see Table 2 ). In addition, $\beta=1.0$ and $\beta=10.0$ were used to illustrate the effect of solute interaction, and the undercooling $\Delta T$ was set at $0.5 \mathrm{~K}$.

The calculated iso- $\beta$ lines $(\beta=1.0$ and $\beta=10.0)$ as a function of alloy compositions are presented in Fig. 7. When $L_{B C}=0$, the iso- $\beta$ line is a straight line; whereas negative $\left(L_{B C}=-\right.$ $125 \mathrm{~kJ} / \mathrm{mol})$ and positive $\left(L_{B C}=125 \mathrm{~kJ} / \mathrm{mol}\right)$ interactions make the iso- $\beta$ lines convex and concave, respectively. Therefore, for a given alloy composition a negative $L_{B C}$ reduces $\beta$ since higher concentrations of solute elements have to be present in the alloy melt to obtain the same $\beta$ value (e.g. $\beta=10.0$ ); while a positive $L_{B C}$ increases $\beta$, compared with the case of $L_{B C}=0$ (the solid line). This means that an attractive solute interaction leads to a weaker growth restriction while a repulsive solute interaction results in a stronger growth restriction. In addition, our analysis has confirmed that the solute interaction in the solid phase has very little effect on the overall $\beta$ value, which was also reported by Quested et al. [28] in the their work on thermodynamic modelling of $Q$.

The largest change in $\beta$ value $\left(L_{B C}= \pm 125 \mathrm{~kJ} / \mathrm{mol}\right.$ and $\left.\beta=10\right)$ in this case is only $\pm 6 \%$ (Fig. $7 \mathrm{~b})$. In fact, most of the absolute $L_{B C}$ values obtained from the thermodynamic database COST 507 (see Table 2) are much less than $125 \mathrm{~kJ} / \mathrm{mol}$. Therefore, it is reasonable to assume that there are no interactions between solutes for the calculation of the overall $\beta$ of dilute multicomponent alloys. Fig. 7, therefore, provides a theoretical justification for the linear additivity of $\beta$ (Eq. (19)).

\subsection{Applicability of $\beta$}

In this work, we have derived a new parameter, $\beta$, to quantify the growth restriction during solidification (Eq. (18)), which equals to the ratio of the liquid phase fraction over the solid phase fraction at an undercooling of $\Delta T$ (Eq. (20)). Eq. (18) suggests that in a binary alloy there are three key factors that affect $\beta$ : the nature of the solute ( $m$ and $k$ ), solute concentration $\left(C_{0}\right)$ and undercooling $(\Delta T)$. In this section we will discuss the applicability of $\beta$ in terms of the ranges of such parameters. 
For a given alloy (fixed $m$ and $k$ ) solidifying under a fixed undercooling $(\Delta T)$, it is straightforward that growth restriction increases linearly with increasing solute concentration $\left(C_{0}\right)$ according to Eq. (18). This is well understood theoretically and has been confirmed extensively by experiments through grain refinement (see review in [19]). However, further analysis of Figs. 2 and 3 reveals that for a given binary alloy solidifying under a given undercooling $(\Delta T)$ there is a critical concentration $\left(C^{*}\right)$, below which $\beta=0$. Let $\beta=0$, one obtains $C^{*}$ from Eq. (18):

$$
C^{*}=\frac{k \Delta T}{m(k-1)}
$$

Eq. (22) suggests that for a given alloy $C^{*}$ is a function of undercooling $\Delta T$; and $C^{*}$ increases with increasing undercooling $\Delta T$. As schematically illustrated in Fig. 8 for both eutectic and peritectic systems, $C^{*}$ marks the solute concentration at which the solidification undercooling equals to the freezing range of the alloy. For given undercooling $\Delta T$, when $C_{0}<C^{*}$, solidification becomes partitionless (non-equilibrium solidification) and therefore there is no growth restriction $(\beta=0)$; whereas when $C_{0}>C^{*}$, growth restriction increases with increasing $C_{0}$ as described by Eq. (18).

Similarly, one can work out the conditions for partitionless solidification of multicomponent systems. Let $\beta=0$ in Eq. (19), one has:

$$
\sum_{i=1}^{n} \frac{m_{i} c_{o i}\left(k_{i}-1\right)}{\Delta T}-\sum_{i=1}^{n} k_{i}=0
$$

For a given solidification condition, $\Delta T$ is a constant, and hence,

$$
\Delta T=\frac{\sum_{i=1}^{n} m_{i} C_{o i}\left(k_{i}-1\right)}{\sum_{i=1}^{n} k_{i}}
$$

In consideration of Eq. (1), Eq. (24) becomes:

$$
\Delta T=\sum_{i=1}^{n} P_{i}
$$

where $P_{i}$ is the freezing range of the constituent binary systems in a multicomponent system. When $\sum_{i=1}^{n} P_{i} \leq \Delta T$, solidification becomes partitionless and there is no growth restriction; while when $\sum_{i=1}^{n} P_{i}>\Delta T$, the overall growth restriction is described by Eq. (19). 
As demonstrated clearly in Fig. 2, $Q$ has its limitation to quantify the effect of solutes in a multicomponent system on growth restriction even at a fixed undercooling, since the intercept in Fig. 2 for each solute is different, especially for the peritectic-forming elements. For eutectic-forming elements $(k<1)$, such as $\mathrm{Fe}(k=0.023)$ and $\mathrm{Si}(k=0.12)$, the growth restriction coefficient $\left(2 / \lambda^{2}\right)$ increases with increasing $Q$ within a reasonably small band. This suggests that $Q$ may be used as a rough estimate of the growth restriction coefficient in such cases (Figs. 2 and 5). However, for peritectic-forming elements $(k>1)$, such as Ti $(k=$ 7.4), $Q$ is not suitable for quantifying growth restriction (Fig. 5). This is likely the reason why the grain size is not a monotonic function of $Q$ reported in Refs. [46, 47]. In contrast to $Q$, the growth restriction coefficient $\left(2 / \lambda^{2}\right)$ is a unique function of $\beta$ (Fig. 3). Therefore, $\beta$ is applicable to all solutes regardless of their $k$ values (Fig. 6),

From Eq. (17), one obtains the relationship between $\alpha$ and $\beta$ :

$$
\beta=\frac{1-\alpha}{\alpha}
$$

Then, one can easily obtain the following limiting conditions:

- when $\alpha \rightarrow 0, \beta \rightarrow \infty, 2 / \lambda^{2} \rightarrow \beta$;

- when $\alpha \rightarrow 1, \beta \rightarrow 0,2 / \lambda^{2} \rightarrow \beta / 3$.

Fig. 9 compares the growth velocity data obtained from the phase field simulations with the predictions from Fan and Lu model [53], Maxwell and Hellawell model [25] and the Zener approximation [52]. Fig. 9 suggests that the Maxwell and Hellawell model [25] and Zener approximation [52] are only applicable to cases with very small solute supersaturation $(\alpha \rightarrow 0$, $\beta \rightarrow \infty)$ and is not suitable for dilute alloys, where solute supersaturation can easily approach unity $(\alpha \rightarrow 1, \beta \rightarrow 0)$. In contrast, the good agreement between the phase field simulation and analytical modelling in Fig. 9 suggests that $\beta$ is applicable to the full range of solute supersaturation, i.e., $0<\alpha<1$.

\subsection{Physical origin of growth restriction}

Generally, it is understood that growth restriction is a direct result of enrichment/depletion of solute elements at the solid/liquid interface due to the differential partitioning of solute elements at the solid/liquid interface during solidification. However, the atomistic mechanism of growth restriction is worthy of further consideration. Kinetically, the growth velocity is 
determined by the rate of atomic attachment at the solid/liquid interface and the rate of supply of such atoms to the interface from the bulk liquid. It is well understood that the controlling factor for crystal growth is the rate of atomic supply since the atomic attachment at the interface is easy under relatively small undercooling. During the solidification of alloys containing eutectic-forming elements $(k<1)$, the controlling factor for crystal growth is the supply of the solvent atoms. The enrichment of solute elements at the interface blocks the supply of solvent atoms and consequently leads to a decreased growth velocity of the solid. Similarly, during the solidification of alloys containing peritectic-forming elements $(k>1)$, the supply of solute atoms becomes the controlling factor for crystal growth. The depletion of solute elements (equivalent to enrichment of solvent) at the interface blocks the supply of solute atoms that is critical for crystal growth, leading to a decreased growth velocity of the solid. Therefore, it can be concluded that the physical origin of growth restriction is the blockage of the supply of the critical elements for crystal growth, i.e., solvent atoms in the case of eutectic-forming elements and solute atoms in the case of peritectic-forming elements.

\subsection{Effect of solutes on the solidification microstructure}

Growth restriction should be understood in the overall context of microstructural evolution during solidification. A solidification microstructure is usually determined by the number of nucleation events and their growth behaviour, which in turn are affected by alloy composition, the potency and efficiency of the nucleant particles and solidification conditions. The effect of solute concentrations on solidification microstructure should be discussed in this overall context.

Firstly, solutes affect nucleation potency and hence nucleation undercooling through adsorption of solutes onto the liquid/substrate interface [59]. Such solute segregation at the interface can either enhance or impede heterogeneous nucleation depending on whether the segregated elements decrease or increase the lattice misfit between the solid and the substrate. For instance, adsorption of $\mathrm{Ti}$ on the (0001) $\mathrm{TiB}_{2}$ surface forms a monoatomic layer of (112) $\mathrm{Al}_{3}$ Ti 2D compound, which reduces the lattice misfit from the original $-4.2 \%$ (with $\mathrm{TiB}_{2}$ ) to $0.09 \%$ (with $\mathrm{Al}_{3} \mathrm{Ti}$ ), enhancing significantly the heterogeneous nucleation [49]; whereas adsorption of $\mathrm{Zr}$ on the (0001) $\mathrm{TiB}_{2}$ surface destabilizes the (112) $\mathrm{Al}_{3} \mathrm{Ti} 2 \mathrm{D}$ compound and results in the formation of a monoatomic layer of (0001) $\mathrm{Ti}_{2} \mathrm{Zr} 2 \mathrm{D}$ compound, which 
increases the lattice misfit from $0.09 \%$ to $-4.3 \%$, impeding significantly the heterogeneous nucleation [60].

Secondly, the solutes affect columnar to equiaxed transition (CET) when the alloy is dilute or contains a low number density of nucleant particles. In such cases, increasing solute concentration increases the constitutional undercooling and hence the number of heterogeneous nucleation events at the columnar growth front, which in turn promotes CET, leading to a finer equiaxed microstructure.

Finally, solutes affect growth velocity. At the early stage of solidification, defined as the stage between nucleation and morphological instability [61], a crystal remains spherical. The enriched/depleted solutes at the solid/liquid interface have a significant effect on the growth velocity. As shown in Fig. 6, the growth velocity is a unique function of $\beta$, which is linearly proportional to solute concentration under a given solidification condition. However, such growth restriction will be significantly reduced after the morphological instability. During dendritic growth, solute enrichment/depletion will occur in the interdendritic-arm regions, and growth restriction of solutes becomes less significant at the tips of the dendrite arms, resulting in a higher growth velocity at the dendrite arm tips.

\section{Summary}

In this paper, we have demonstrated that the widely used growth restriction factor, $Q$, is not a unique function of the true growth restriction coefficient and therefore has its restriction for quantifying the growth restriction effect of solutes during alloy solidification. It has been shown that the true growth restriction coefficient is a function of $Q$, undercooling $(\Delta T)$ and partition coefficient $(k)$. However, it should be point out that for alloy systems that only contain eutectic-forming elements $(k<1)$, the growth restriction coefficient increases with increasing $Q$ within a reasonably small band. This suggests that $Q$ may be used as a rough estimate of the true growth restriction coefficient in such cases, and explains why $Q$ has been used for quantifying growth restriction for so long in the literature.

To quantify growth restriction effectively, we have derived theoretically a new growth restriction parameter, $\beta$, which incorporates holistically the nature of solutes, solute concentrations and solidification conditions. Theoretical analysis and phase field simulations have confirmed that growth velocity is a unique function of $\beta$ regardless of the nature of solutes, solute concentrations and solidification conditions. The overall $\beta$ of a 
multicomponent system can be either calculated accurately through the ratio of the liquid fraction to the solid fraction, or approximated reasonably by a linear addition of the $\beta$ values of its constituent binary systems. Our analysis suggests that the physical origin of growth restriction is the blockage of the supply of the critical elements for crystal growth, i.e., solvent atoms in the case of eutectic-forming elements and solute atoms in the case of peritectic-forming elements.

In addition, we have shown theoretically that for a given alloy system solidifying under a given undercooling, there is a critical solute concentration $\left(C^{*}\right)$, below which solidification becomes partitionless (non-equilibrium solidification) and therefore there is no growth restriction during solidification in this case. Consequently, extra caution has to be taken when analysing growth restriction in very dilute alloys solidifying under relatively large undercooling.

Furthermore, we have analysed the effect of solute interactions on growth restriction and found that it is reasonable to assume that there are no interactions between solutes for the calculation of the overall $\beta$ of dilute multicomponent alloys. However, when the solute concentrations are high and/or solute interactions are strong, the effect of solute interactions cannot be ignored. A strong attractive solute interaction leads to a weaker growth restriction while a strong repulsive solute interaction results in a stronger growth restriction.

\section{Acknowledgement}

Financial support from the EPSRC (UK) under grant number EP/N007638/1 is gratefully acknowledged. The author would also like to thank Dr I. C. Stone (Brunel University London, UK) and Professor W. Kurz for their constructive comments on the manuscript.

\section{References}

[1] A. Cibula, The mechanism of grain refinement of sand castings in aluminium alloys, J. Inst. Metals, 76 (1949-50) 321-60.

[2] G.P. Ivantsov: Proceedings of the Academy of Sciences USSR, 1951, vol. LXXX1 (2), p. 179-182.

[3] J.W. Rutter, B. Chalmers, A prismatic substructure formed during solidification of metals, Can. J. Physics, 31 (1953) 15-39. 
[4] W.A. Tiller, K.A. Jackson, J.W. Rutter, B. Chalmers, The redistribution of solute atoms during the solidification of metals, Acta Metall. 1 (1953) 428-437.

[5] W. Winegard, B. Chalmers, Supercooling and dendritic freezing in alloys, Trans. ASM, 46 (1954) 1214-1224.

[6] M.H. Burden, J.D. Hunt, Cellular and dendritic growth. I, J. Cryst. Growth 22 (1974) 99108.

[7] J. Hunt, Steady state columnar and equiaxed growth of dendrites and eutectic, Mater. Sci. Eng. 65 (1984) 75-83.

[8] P. Desnain, Y. Fautrelle, J.-L. Meyer, J.-P. Riquet, F. Durand, Prediction of equiaxed grain density in multicomponent alloys, stirred electromagnetically, Acta Metall. Mater. 38 (1990) 1513-1523.

[9] M. Johnsson, Influence of Si and Fe on the grain refinement of aluminium, Z. Metallkde. 85 (1994) 781-785.

[10] G. Chai, L. Bäckerud, L. Arnberg, Relation between grain size and coherency parameters in aluminium alloys, Mater. Sci. Technol. 11 (1995) 1099-1103.

[11] D.G. McCartney, Grain refining of aluminium and its alloys using inoculants, Int. Mater. Rev. 34 (1989) 247-260.

[12] D.A. Granger, in Welch BJ, ed. Light Metals 1998. Warrendale, PA: TMS; 1998. p. 941 952.

[13] M. Easton, D. StJohn, Grain refinement of aluminum alloys: Part I. The nucleant and solute paradigms - A review of the literature, Metall. Mater. Trans. A 30 (1999) 16131623.

[14] F. Crossley, L. Mondolfo, Mechanism of grain refinement in aluminium alloys, JOM 191 (1951) 1143-1151.

[15] G.A. Chadwick, Heterogeneous nucleation of metals from their melts, Metals and Materials 3 (1969) 77-83.

[16] J.F. Wallace: Proceedings of Electric Furnace Conference, 1962, p. 125-39.

[17] L.A. Tarshis, J.L. Walker, J.W. Rutter, Experiments on the solidification structure of alloy castings, Metall. Trans. 2 (1971) 2589-2597.

[18] M.A. Easton, M. Qian, A. Prasad, D.H. StJohn, Recent advances in grain refinement of light metals and alloys, Curr. Opin. Solid State Mater. Sci. 20 (2016) 13-24.

[19] Z. Liu, Review of grain refinement of cast metals through inoculation: Theories and developments, Metall. Mater. Trans. A 48 (2017) 4755-4776. 
[20] A.L. Greer, Overview: Application of heterogeneous nucleation in grain-refining of metals, J. Chem. Phys. 145 (2016) 211704.

[21] L. Zhou, F. Gao, G.S. Peng, N. Alba-Baena, Effect of potent $\mathrm{TiB}_{2}$ addition levels and impurities on the grain refinement of Al, J. Alloys Compd. 689 (2016) 401-407.

[22] M. Qian, A. Ramirez, A. Das, D.H. StJohn, The effect of solute on ultrasonic grain refinement of magnesium alloys, J. Cryst. Growth 312 (2010) 2267-72.

[23] D.H. StJohn, A. Prasad, M.A. Easton, M. Qian, The contribution of constitutional supercooling to nucleation and grain formation, Metall. Mater. Trans. A 46 (2015) 4868-4885.

[24] J.A. Spittle, S.B. Sadli, Effect of alloy variables on grain refinement of binary aluminium alloys with Al-Ti-B, Mater. Sci. Technol. 11 (1995) 533-537.

[25] I. Maxwell, A. Hellawell, A simple model for grain refinement during solidification, Acta Metall. 23 (1975) 229-237.

[26] A.L. Greer, A.M. Bunn, A. Tronche, P.V. Evans, D.J. Bristow, Modelling of inoculation of metallic melts: application to grain refinement of aluminium by Al-Ti-B, Acta Mater. 48 (2000) 2823-2835.

[27] M.A. Easton, D.H. StJohn, A model of grain refinement incorporating alloy constitution and potency of heterogeneous nucleant particles, Acta Mater. 49 (2001) 1867-1878.

[28] T.E. Quested, A.T. Dinsdale, A.L. Greer, Thermodynamic modelling of growthrestriction effects in aluminium alloys, Acta Mater. 53 (2005) 1323-1334.

[29] R. Schmid-Fetzer, A. Kozlov, Thermodynamic aspects of grain growth restriction in multicomponent alloy solidification, Acta Mater. 59 (2011) 6133-6144.

[30] M. Johnsson, Grain refinement of aluminium studied by use of a thermal analytical technique, Thermochimica Acta 256 (1995) 107-121.

[31] F. Hodaj, F. Durand, Equiaxed grains in multicomponent alloys: Effect of growth rate, Acta Mater. 45 (1997) 2121-2127.

[32] M.A. Easton, D.H. StJohn, An analysis of the relationship between grain size, solute content, and the potency and number density of nucleant particles, Metall. Mater. Trans. A 36 (2005) 1911-1920.

[33] D.H. StJohn, M. Qian, M.A. Easton, P. Cao, Z. Hildebrand, Grain refinement of magnesium alloys, Metall. Mater. Trans. A 36 (2005) 1669-1679.

[34] T.V. Atamaneko, D.G. Eskin, L. Zhang, L. Katgerman, Criteria of grain refinement induced by ultrasonic melt treatment of aluminum alloys containing $\mathrm{Zr}$ and $\mathrm{Ti}$, Metall. Mater. Trans. A 41 (2010) 2056-2066. 
[35] I. Toda-Caraballo, E.I. Galindo-Nava, P.E.J. Rivera-Díaz-del-Castillo, Understanding the factors influencing yield strength on Mg alloys, Acta Mater. 75 (2014) 287-296.

[36] H. Men, Z. Fan, Effects of solute content on grain refinement in an isothermal melt, Acta Mater. 59 (2011) 2704-2712.

[37] D.H. StJohn, M. Qian, M.A. Easton, P. Cao, The Interdependence Theory: The relationship between grain formation and nucleant selection, Acta Mater. 59 (2011) 4907-4921.

[38] A. Prasad, L. Yuan, P.D. Lee, D.H. StJohn, The Interdependence model of grain nucleation: A numerical analysis of the Nucleation-Free Zone, Acta Mater. 61 (2013) 5914-5927.

[39] A. Becerra, M. Pekguleryuz, Effects of zinc, lithium, and indium on the grain size of magnesium, J. Mater. Res. 24 (2009) 1722-1729.

[40] D.H. StJohn, M.A. Easton, M. Qian, J.A. Taylor, Grain refinement of magnesium alloys: A review of recent research, theoretical developments, and their application, Metall. Mater. Trans. A 44 (2013) 2935-2949.

[41] M.J. Bermingham, S.D. McDonald, M.S. Dargusch, D.H. StJohn, The mechanism of grain refinement of titanium by silicon, Scripta Mater. 58 (2008) 1050-1053.

[42] M. Qian, P. Cao, M.A. Easton, S.D. McDonald, D.H. StJohn, An analytical model for constitutional supercooling-driven grain formation and grain size prediction, Acta Mater. 58 (2010) 3262-3270.

[43] M.A. Easton, D.H. StJohn, Improved prediction of the grain size of aluminum alloys that includes the effect of cooling rate, Mater. Sci. Eng. A 486 (2008) 8-13.

[44] Q. Du, Y. Li, An extension of the Kampmann-Wagner numerical model towards as-cast grain size prediction of multicomponent aluminum alloys, Acta Mater. 71 (2014) 380389.

[45] D. Shu, B. Sun, J. Mi, P.S. Grant, A quantitative study of solute diffusion field effects on heterogeneous nucleation and the grain size of alloys, Acta Mater. 59 (2011) 21352144.

[46] H. Xu, L.D. Xu, S.J. Zhang, Q. Han, Effect of the alloy composition on the grain refinement of aluminum alloys, Scripta Mater. 54 (2006) 2191-2196.

[47] Z. Liu, F. Wang, D. Qiu, J.A. Taylor, M. Zhang, The effect of solutes on the grain refinement of cast Zn, Metall. Mater. Trans. A 44 (2013) 4025-4030.

[48] Standard test procedure for aluminium alloy grain refiners (TP-1). Washington, DC: The Aluminium Association; 1990. 
[49] Z. Fan, Y. Wang, Y. Zhang, T. Qin, X.R. Zhou, G.E. Thompson, T. Pennycook, T. Hashimoto, Grain refining mechanism in the Al/Al-Ti-B system, Acta Mater. 84 (2015) 292-304.

[50] L. Zhou, The role of solute elements on grain refinement of Al alloys with Al-Ti-B inoculations, Doctoral thesis, Brunel University London, Uxbridge, 2015.

[51] H.B. Aaron, D. Fainstein, G.R. Kotler, Diffusion-limited phase transformations: A comparison and critical evaluation of the mathematical approximations, J. Appl. Phys. 41 (1970) 4404-4410.

[52] C. Zener, Theory of growth of spherical precipitates from solid solution, J. Appl. Phys. 20 (1949) 950-953.

[53] Z. Fan, S.Z. Lu, A simple model for spherical growth in alloy solidification, IOP Conf. Series: Materials Science and Engineering 117 (2016) 012016.

[54] W.J. Boettinger, J.A. Warren, C. Beckermann, A. Karma, Phase-field simulation of solidification, Annu. Rev. Mater. Res. 32 (2002) 163-194.

[55] I. Steinbach, Phase-field models in materials science, Modelling Simul. Mater. Sci. Eng. 17 (2009) 073001.

[56] M. Asta, C. Beckermann, A. Karma, W. Kurz, R. Napolitano, M. Plapp, G. Purdy, M. Rappaz, R. Trivedi, Solidification microstructures and solid-state parallels: Recent developments, future directions, Acta Mater. 57 (2009) 941-971.

[57] www.micress.de

[58] J. Eiken, A phase-field model for technical alloys solidification, Doctoral thesis, Aachen University, Aachen, 2010.

[59] Z. Fan, An epitaxial model for heterogeneous nucleation on potent substrates, Metall. Mater. Trans. A 44 (2013) 1409-1418.

[60] Y. Wang, B. Jiang, T. Hashimoto, X.R. Zhou, Q.M. Ramasse, Z. Fan, Mechanism for Zr poisoning of Al-Ti-B grain refiner, to be submitted to Acta Mater. 2018.

[61] W.W. Mullins, R.F. Sekerka, Morphological stability of a particle growing by diffusion or heat flow, J. Appl. Phys. 34 (1963) 323-329. 


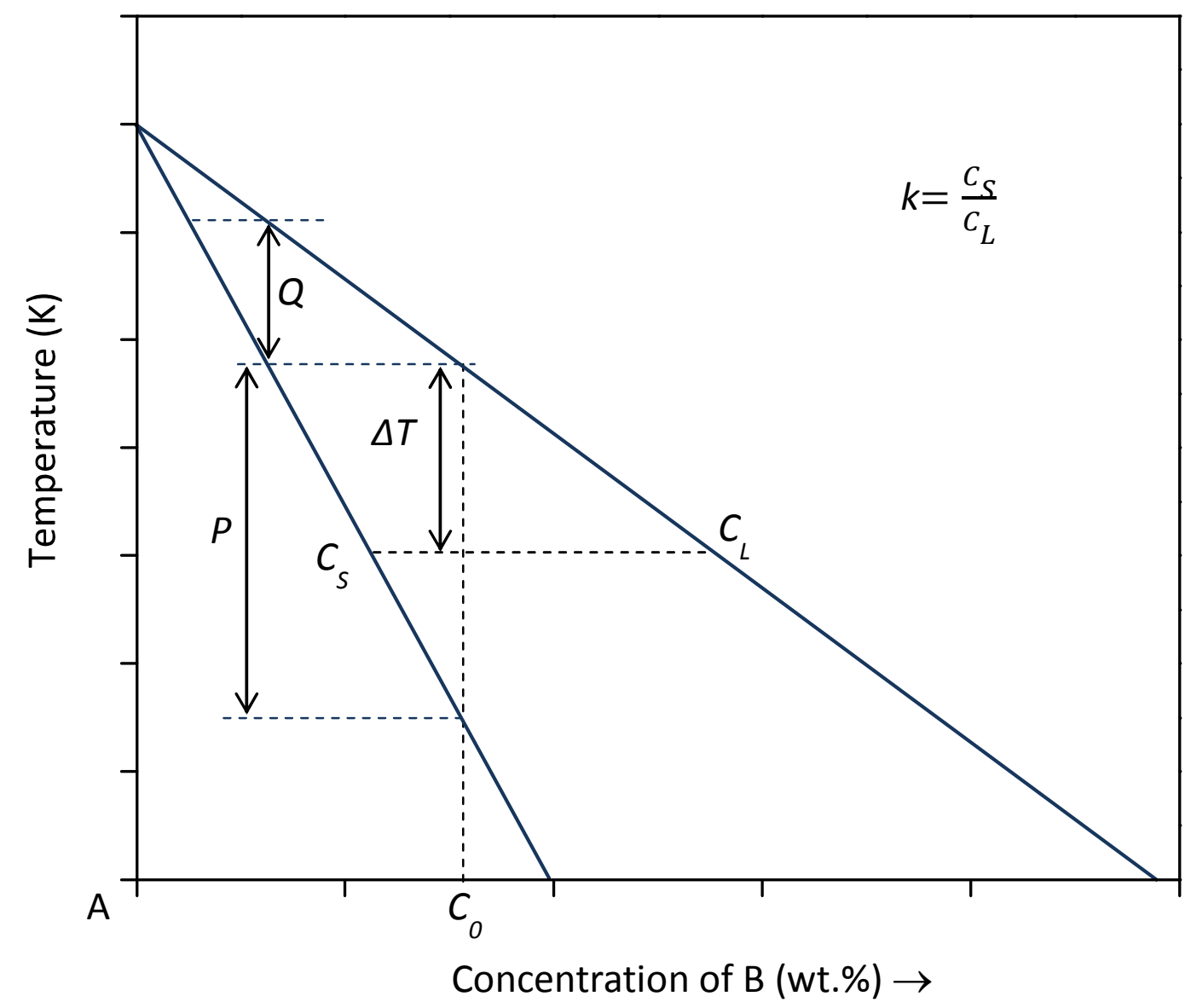

Fig. 1 A schematic illustration of a linear phase diagram of the binary A-B system. 


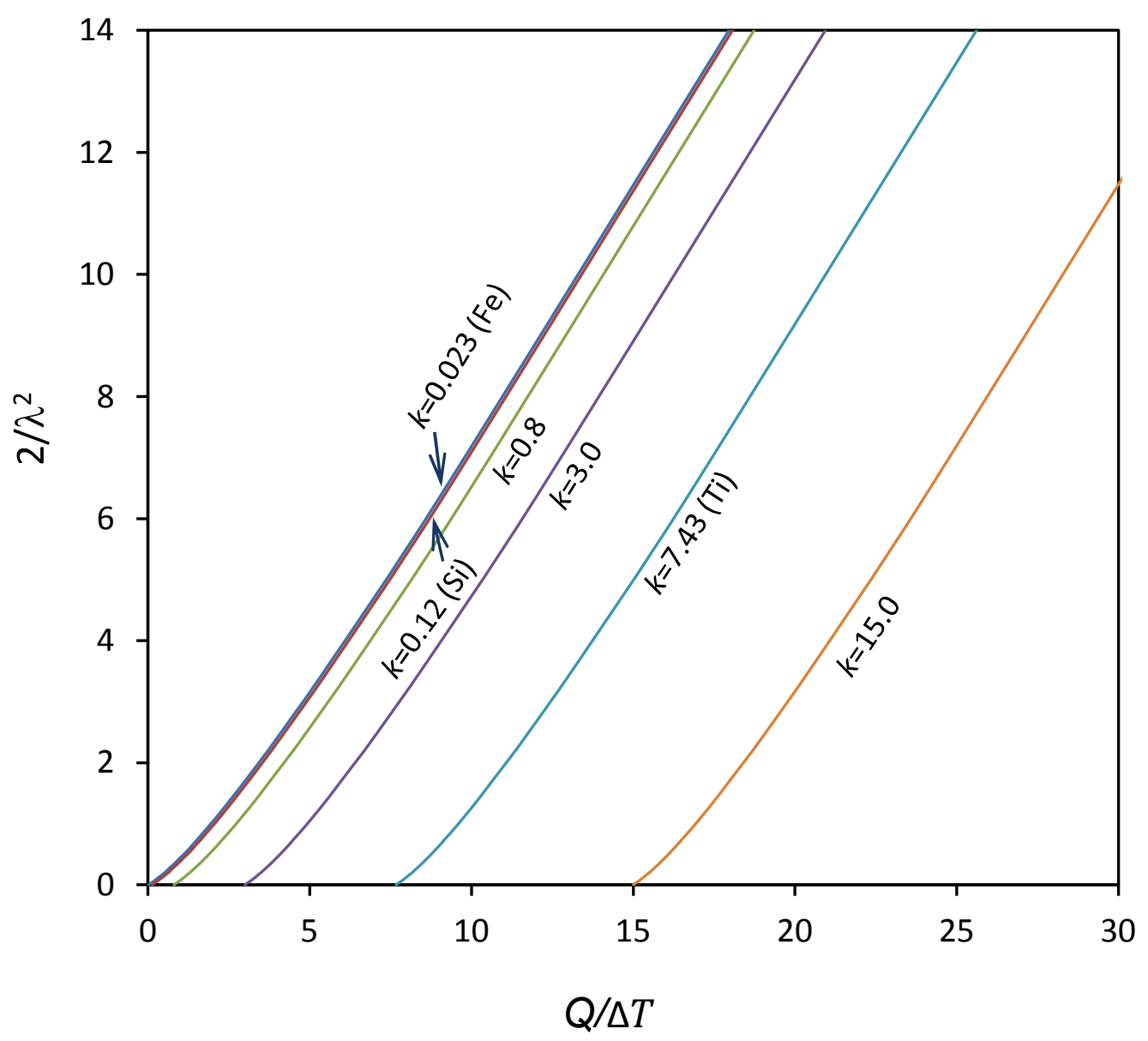

Fig. 2 Growth restriction coefficient $\left(2 / \lambda^{2}\right)$ for spherical growth during solidification of binary Al-alloys calculated from Eqs. (16) and (17) as a function of $Q / \Delta T$. Please note that the intercept of $2 / \lambda^{2}$ at $Q / \Delta T$ axis is $k$ (the solute partition coefficient). 


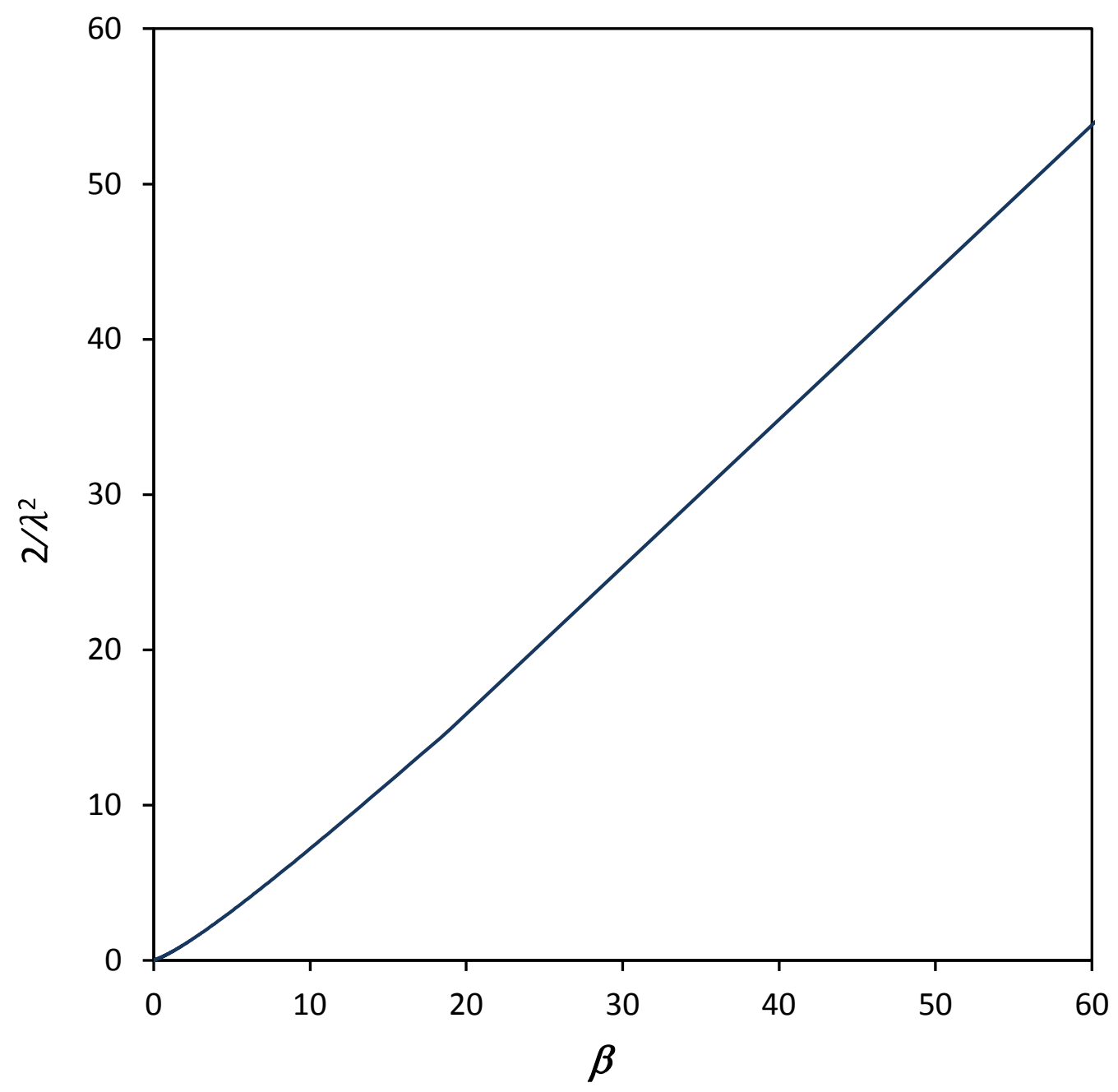

Fig. 3 Growth restriction coefficient $\left(2 / \lambda^{2}\right)$ for spherical growth during solidification of binary alloys as a function of the new growth restriction parameter, $\beta$, showing that the growth restriction coefficient is a unique function of $\beta$, regardless of the nature of solutes, solute concentrations and solidification conditions. 


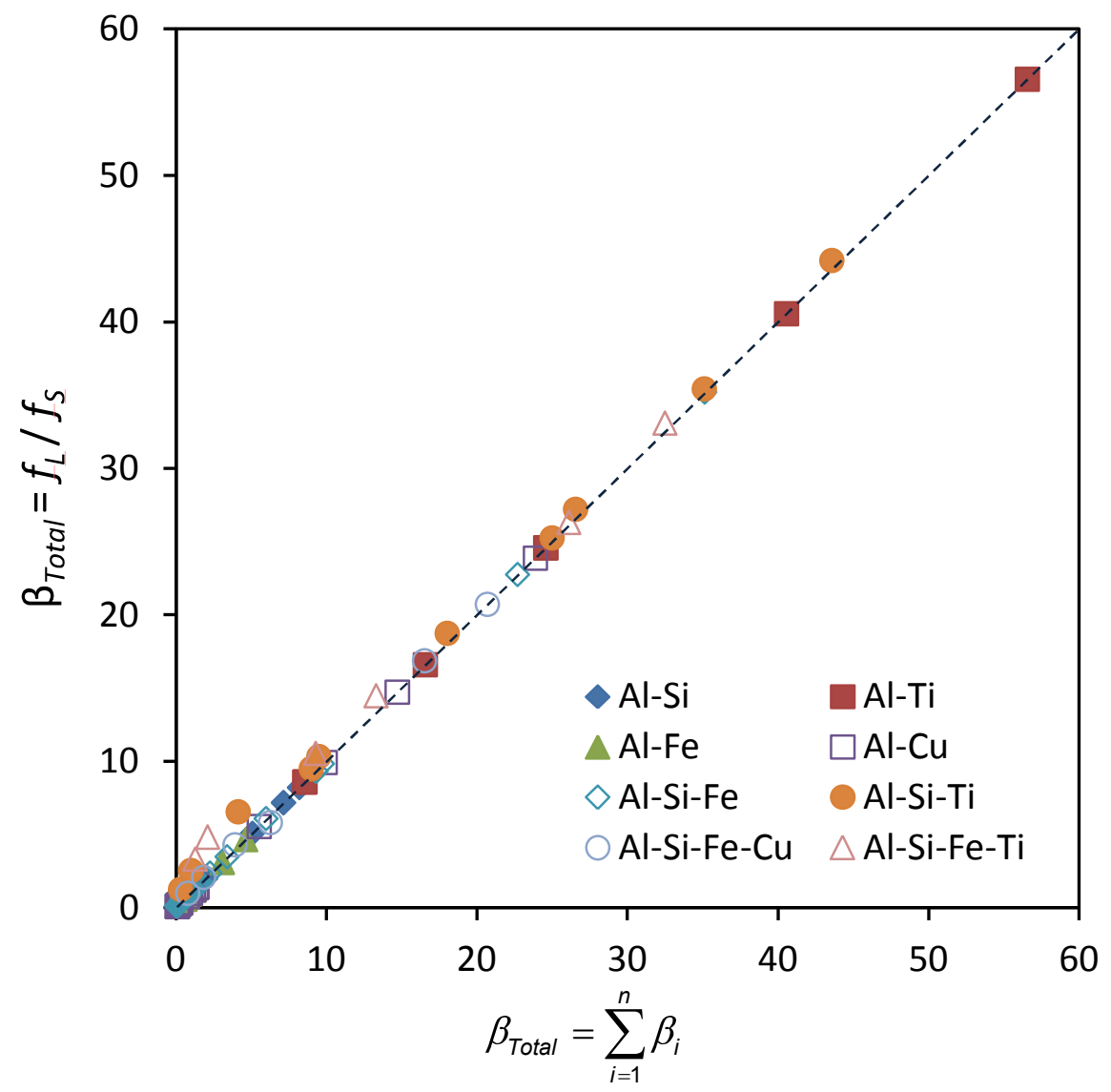

Fig. 4 Comparison between the true $\beta$ values calculated from Eq. (20) and those approximated by linear additivity (Eq. (19)) showing that the linear addition of the individual $\beta$ of the constituent solutes is a good approximation of the true $\beta$ values for multicomponent systems. 


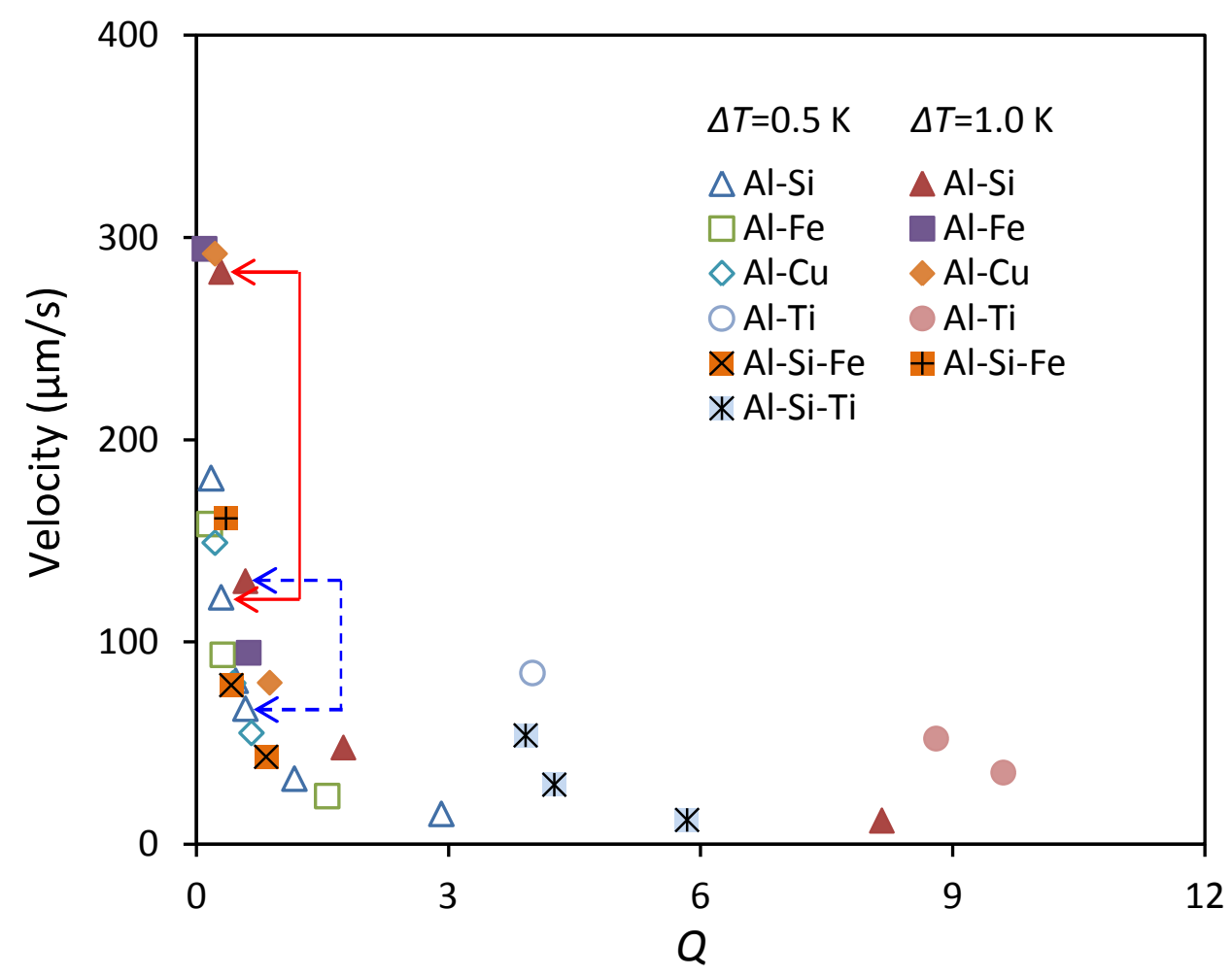

Fig. 5 Growth velocity obtained by phase field simulations as a function of $Q$ for various binary and ternary Al-alloys solidifying under different levels of undercooling $(0.5 \mathrm{~K}$ and $1.0 \mathrm{~K}$ ), showing that the growth velocity is not a unique function of $Q$. The red solid arrows mark the Al-0.05Si alloy, and the blue dashed arrows mark the Al-0.1Si alloy. 


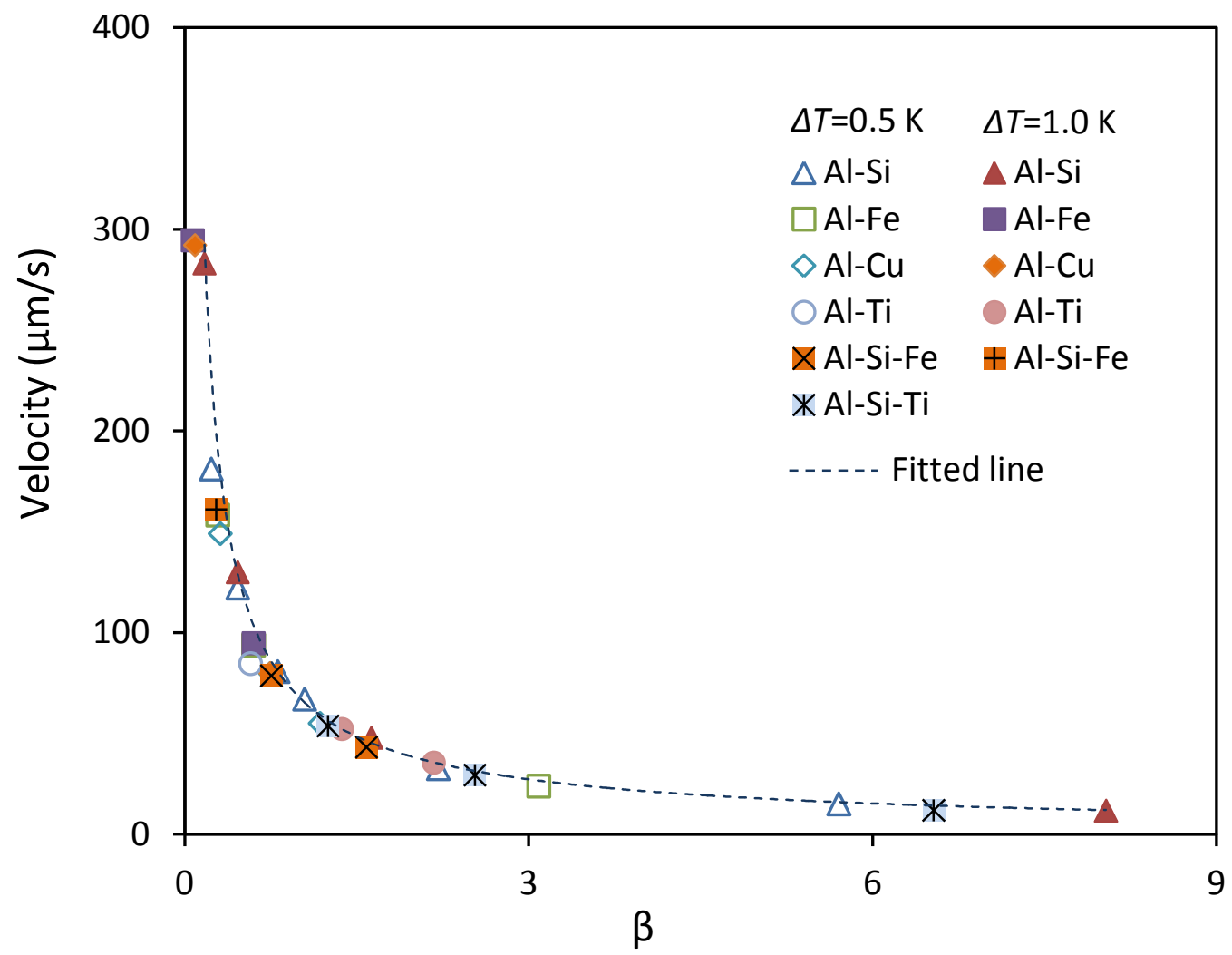

Fig. 6 Growth velocity obtained by phase field simulations as a function of $\beta$ for various binary and ternary Al-alloys solidifying under different levels of undercooling $(0.5 \mathrm{~K}$ and $1.0 \mathrm{~K}$ ), showing that growth velocity is a unique function of $\beta$, regardless of the nature of solutes, solute concentrations and solidification conditions. 

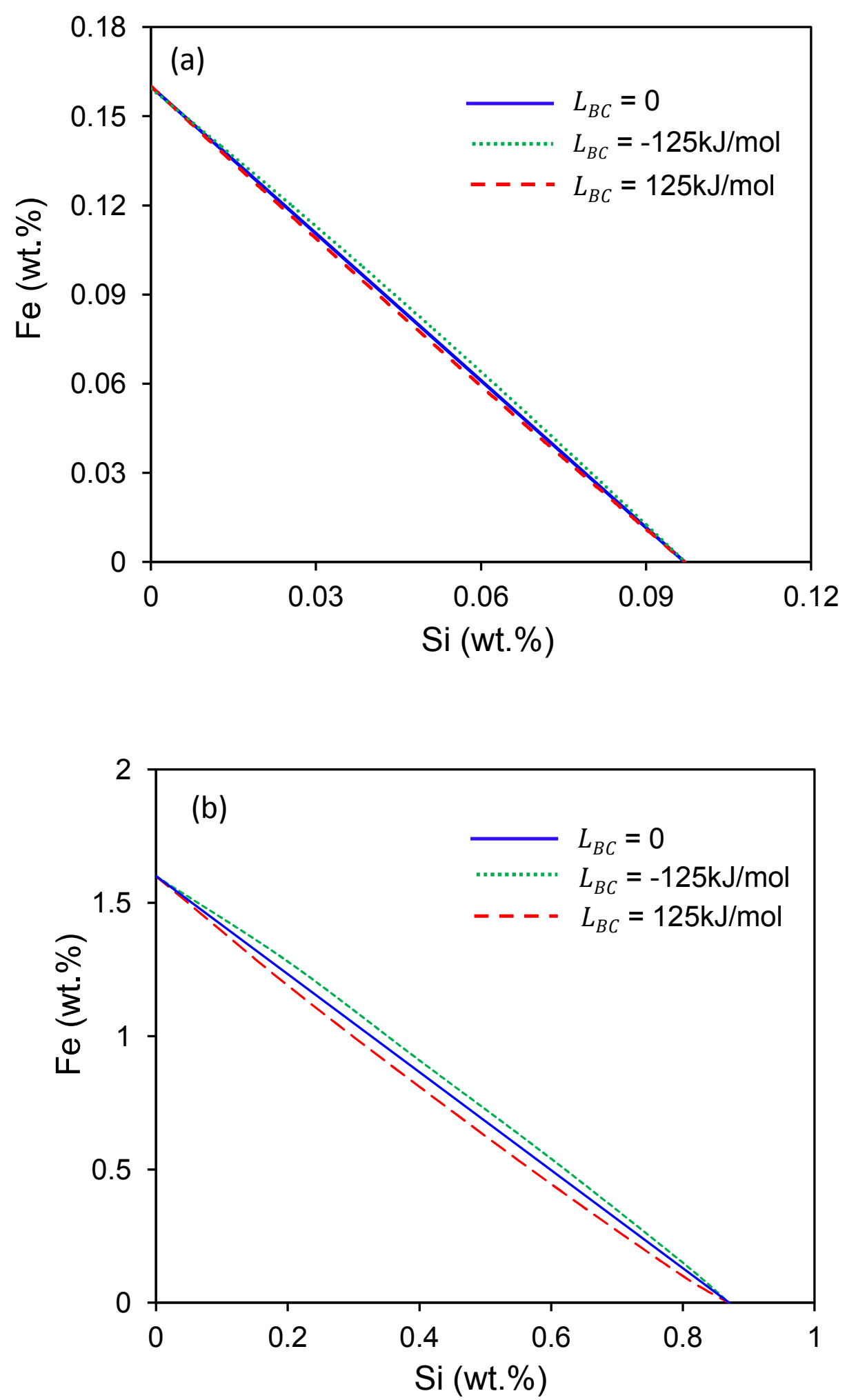

Fig. 7 Calculated iso- $\beta$ lines for the ternary Al-Fe-Si alloys by imposing a very strong interaction between $\mathrm{Fe}$ and $\mathrm{Si}\left(L_{B C}= \pm 125 \mathrm{~kJ} / \mathrm{mole}\right)$ showing the effect of solute interactions on growth restriction, where the $\beta$ values are (a) $\beta=1.0$; and (b) $\beta=10$. 

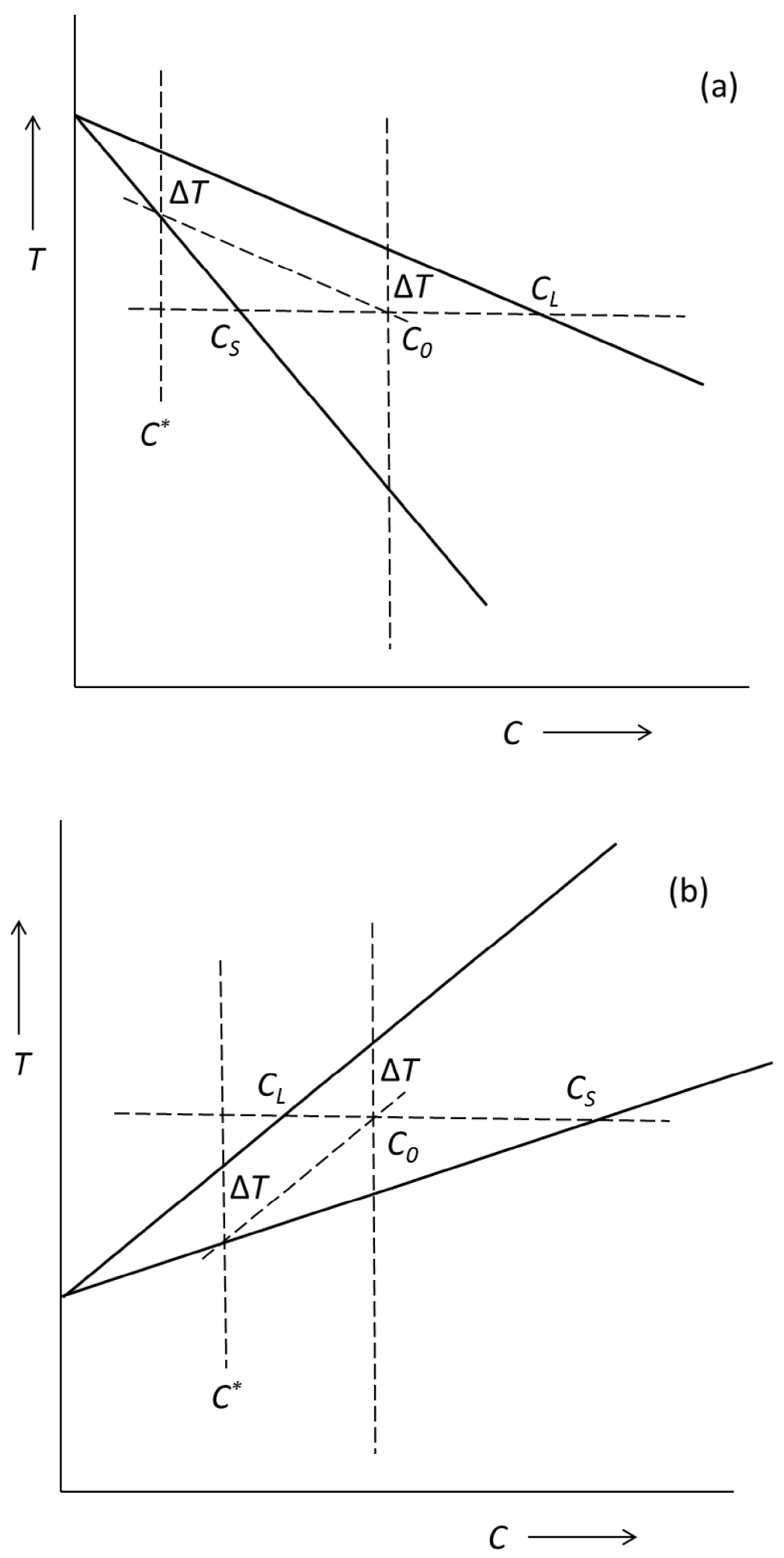

Fig. 8 Schematic illustration of the concept of critical solute concentration $C^{*}$ for binary alloy systems: (a) the eutectic system; and (b) the peritectic system. In both cases, When $C_{0}<C^{*}$, solidification becomes partitionless and therefor there is no growth restriction $(\beta=0)$; whereas when $C_{0}>C^{*}$, growth restriction increases with increasing $C_{0}$ as described by Eq. (18). 


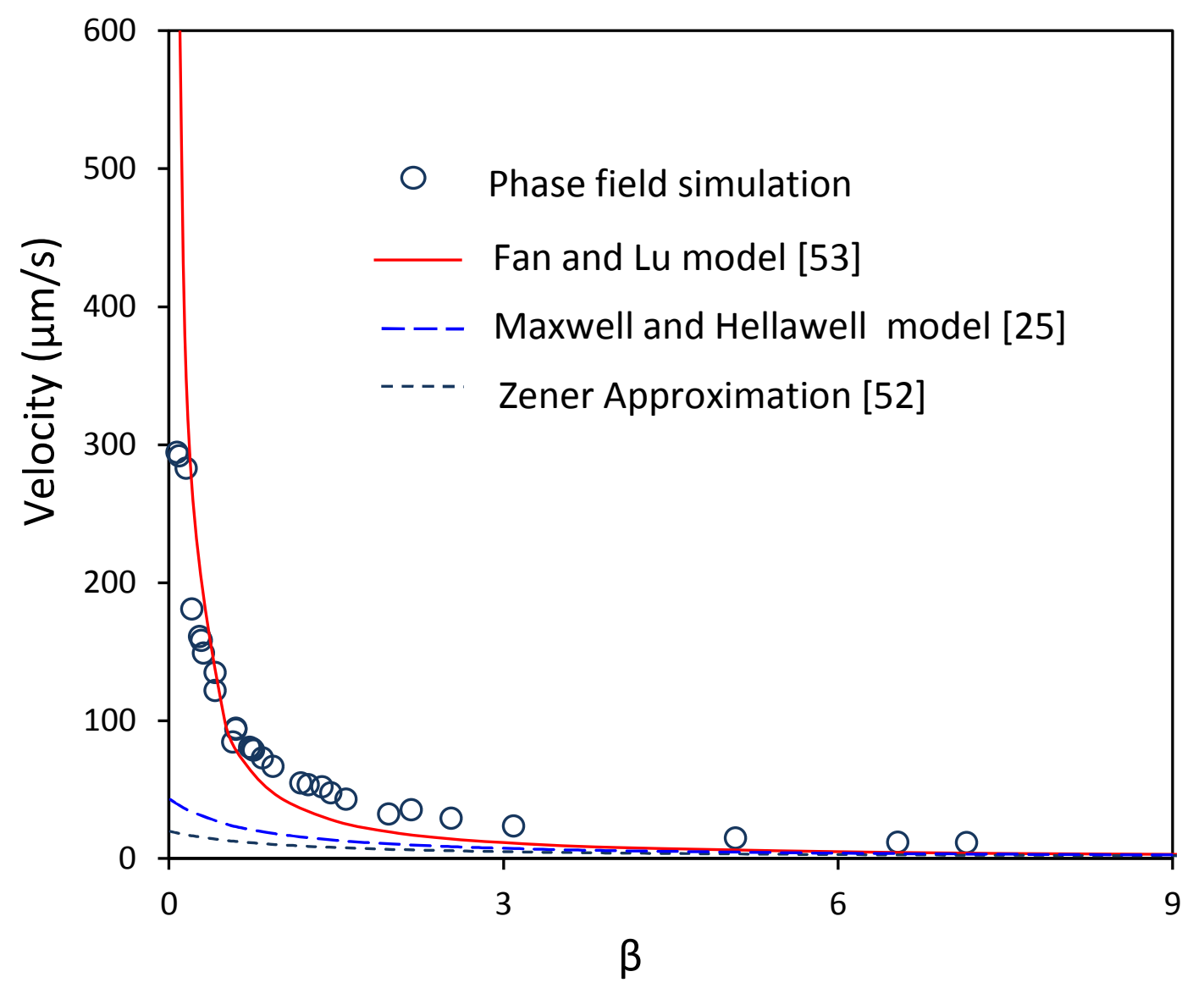

Fig. 9. Comparison of the relationship between growth velocity and $\beta$ obtained from phase field simulations (open circles), Fan and Lu model [53] (solid line), Maxwell and Hellawell model [25] (long dashed line) and Zener approximation [52] (short dashed line). A relatively large radius $(r=1000 \mu \mathrm{m})$ was used for all model calculations in order to compare with phase field simulations where a planar interface was adopted. 
Table 1 List of the main parameters used in the phase field simulation.

\begin{tabular}{ccccl}
\hline$\gamma$ & $D_{i}$ & $D_{S}$ & $m$ & \\
$\left(\mathrm{~J} / \mathrm{cm}^{2}\right)$ & $\left(\mathrm{cm}^{2} / \mathrm{s}\right)$ & $\left(\mathrm{cm}^{2} / \mathrm{s}\right)$ & $(\mathrm{K} / \mathrm{wt} \%)$ & \\
\hline & & & $-6.62(\mathrm{Al}-\mathrm{Si})$ & $0.12(\mathrm{Al}-\mathrm{Si})$ \\
& & & $-3.184(\mathrm{Al}-\mathrm{Fe})$ & $0.023(\mathrm{Al}-\mathrm{Fe})$ \\
$1.0 \times 10^{-5}$ & $2.0 \times 10^{-4}$ & $1.0 \times 10^{-8}$ & $-2.502(\mathrm{Al}-\mathrm{Cu})$ & $0.13(\mathrm{Al}-\mathrm{Cu})$ \\
& & & $24.89(\mathrm{Al}-\mathrm{Ti})$ & $7.43(\mathrm{Al}-\mathrm{Ti})$ \\
\hline
\end{tabular}

Notes: $\gamma$ is solid/liquid interfacial energy; $D_{i}$ is solute diffusion coefficient in the liquid; $D_{S}$ is solute diffusion coefficient in the solid. 
Table 2 List of the interaction parameters $\left(L_{B C}\right)$ for solutes in liquid Al-alloys at $930 \mathrm{~K}$.

\begin{tabular}{cc}
\hline Solute pairs & $L_{B C}(\mathrm{~kJ} / \mathrm{mol})$ \\
\hline $\mathrm{Cu}-\mathrm{Fe}$ & 33.9 \\
$\mathrm{Cu}-\mathrm{Si}$ & -24.9 \\
$\mathrm{Cu}-\mathrm{Mg}$ & -28.9 \\
$\mathrm{Cu}-\mathrm{Ni}$ & 12.8 \\
$\mathrm{Cu}-\mathrm{V}$ & 82.5 \\
$\mathrm{Cu}-\mathrm{Zn}$ & -28.9 \\
$\mathrm{Cu}-\mathrm{Ti}$ & -12.2 \\
$\mathrm{Fe}-\mathrm{Si}$ & -125.4 \\
$\mathrm{Fe}-\mathrm{Ti}$ & -51.0 \\
$\mathrm{Fe}-\mathrm{Ni}$ & -12.8 \\
$\mathrm{Fe}-\mathrm{V}$ & -32.9 \\
$\mathrm{Si}-\mathrm{Mg}$ & -54.2 \\
$\mathrm{Si}-\mathrm{Zn}$ & 8.5 \\
$\mathrm{Ti}-\mathrm{V}$ & 7.6 \\
\hline
\end{tabular}


Appendix: Summary of alloy composition, solidification condition and the corresponding $Q$, $\beta$ (calculated from $f_{L} / f_{S}$ ) and the corresponding growth velocity, which are presented in Figs. 4, 5 and 6.

\begin{tabular}{|c|c|c|c|c|c|}
\hline Alloy & Concentration (wt.\%) & Undercooling (K) & $Q(\mathrm{~K})$ & $\beta$ & Velocity $(\mu \mathrm{m} / \mathrm{s})$ \\
\hline \multirow[t]{10}{*}{$\mathrm{Al}-\mathrm{Si}$} & 0.05 & 0.5 & 0.29 & 0.46 & 122 \\
\hline & 0.1 & 0.5 & 0.58 & 1.04 & 67 \\
\hline & 0.08 & 0.5 & 0.46 & 0.81 & 80.7 \\
\hline & 0.03 & 0.5 & 0.17 & 0.23 & 181 \\
\hline & 0.2 & 0.5 & 1.16 & 2.21 & 32.4 \\
\hline & 0.5 & 0.5 & 2.91 & 5.7 & 15 \\
\hline & 0.05 & 1.0 & 0.29 & 0.17 & 283 \\
\hline & 0.1 & 1.0 & 0.58 & 0.46 & 130 \\
\hline & 0.3 & 1.0 & 1.75 & 1.63 & 47.7 \\
\hline & 1.4 & 1.0 & 8.15 & 8.03 & 11.6 \\
\hline \multirow[t]{5}{*}{$\mathrm{Al}-\mathrm{Fe}$} & 0.05 & 0.5 & 0.15 & 0.29 & 158.2 \\
\hline & 0.1 & 0.5 & 0.31 & 0.6 & 93.7 \\
\hline & 0.5 & 0.5 & 1.55 & 3.09 & 23.8 \\
\hline & 0.03 & 1.0 & 0.09 & 0.07 & 294.5 \\
\hline & 0.2 & 1.0 & 0.62 & 0.6 & 94.6 \\
\hline \multirow[t]{5}{*}{$\mathrm{Al}-\mathrm{Cu}$} & 0.1 & 0.5 & 0.22 & 0.31 & 149.1 \\
\hline & 0.2 & 0.5 & 0.44 & 0.74 & 79.6 \\
\hline & 0.3 & 0.5 & 0.65 & 1.18 & 54.9 \\
\hline & 0.1 & 1.0 & 0.22 & 0.09 & 292 \\
\hline & 0.4 & 1.0 & 0.87 & 0.74 & 79.8 \\
\hline \multirow[t]{4}{*}{ Al-Ti } & 0.025 & 0.5 & 4.0 & 0.57 & 84.5 \\
\hline & 0.1 & 0.5 & 16.0 & 24.57 & 1.7 \\
\hline & 0.06 & 1.0 & 9.6 & 2.17 & 35.4 \\
\hline & 0.055 & 1.0 & 8.8 & 1.37 & 52.2 \\
\hline \multirow[t]{3}{*}{ Al-Fe-Si } & $0.05(\mathrm{Fe}), 0.05(\mathrm{Si})$ & 0.5 & 0.41 & 0.76 & 78.6 \\
\hline & $0.1(\mathrm{Fe}), 0.1(\mathrm{Si})$ & 0.5 & 0.83 & 1.58 & 43.09 \\
\hline & $0.03(\mathrm{Fe}), 0.05(\mathrm{Si})$ & 1.0 & 0.35 & 0.27 & 161.1 \\
\hline \multirow[t]{3}{*}{ Al-Si-Ti } & $0.05(\mathrm{Si}), 0.025(\mathrm{Ti})$ & 0.5 & 4.26 & 2.53 & 29.3 \\
\hline & $0.015(\mathrm{Si}), 0.024(\mathrm{Ti})$ & 0.5 & 3.92 & 1.25 & 53.6 \\
\hline & $0.2(\mathrm{Si}), 0.03(\mathrm{Ti})$ & 0.5 & 5.84 & 6.53 & 11.8 \\
\hline
\end{tabular}




\begin{tabular}{cccc}
\hline Al-Si-Fe- & $1.0(\mathrm{Si}), 1.0(\mathrm{Fe}), 1.0(\mathrm{Cu})$ & 0.5 & 20.71 \\
$\mathrm{Cu}$ & $0.3(\mathrm{Si}), 0.2(\mathrm{Fe}), 0.5(\mathrm{Cu})$ & 0.5 & 5.81 \\
& $0.05(\mathrm{Si}), 0.05(\mathrm{Fe}), 0.05(\mathrm{Cu})$ & 0.5 & 0.98 \\
& $0.1(\mathrm{Si}), 0.1(\mathrm{Fe}), 0.1(\mathrm{Cu})$ & 0.5 & 2.05 \\
& $0.2(\mathrm{Si}), 0.2(\mathrm{Fe}), 0.2(\mathrm{Cu})$ & 0.5 & 4.28 \\
& $0.8(\mathrm{Si}), 0.8(\mathrm{Fe}), 0.8(\mathrm{Cu})$ & 0.5 & 16.84 \\
Al-Si-Fe- & $0.1(\mathrm{Si}), 0.1(\mathrm{Fe}), 0.025(\mathrm{Ti})$ & 0.5 & 4.81 \\
$\mathrm{Ti}$ & $0.05(\mathrm{Si}), 0.05(\mathrm{Fe}), 0.05(\mathrm{Ti})$ & 0.5 & 10.54 \\
& $0.1(\mathrm{Si}), 0.1(\mathrm{Fe}), 0.1(\mathrm{Ti})$ & 0.5 & 26.31 \\
& $0.1(\mathrm{Si}), 0.1(\mathrm{Fe}), 0.12(\mathrm{Ti})$ & 0.5 & 33.09 \\
& $0.05(\mathrm{Si}), 0.05(\mathrm{Fe}), 0.025(\mathrm{Ti})$ & 0.5 & 3.32 \\
& $0.1(\mathrm{Si}), 0.1(\mathrm{Fe}), 0.06(\mathrm{Ti})$ & 0.5 & 14.47 \\
\hline
\end{tabular}

